\title{
Emergência de Plantas da Família Convolvulaceae influenciada pela Profundidade da Semente no Solo e Cobertura com Palha De Cana-De-AçÚCAR ${ }^{1}$
}

\author{
Emergence of Convolvulaceae Family Species Influenced by Sowing Depth in the Soil and \\ Sugarcane Straw Cover
}

\author{
LABONIA, V.D.S. ${ }^{2}$, CARVALHO, S.J.P. ${ }^{3}$, MONDO, V.H.V. ${ }^{3}$, CHIOVATO, M.G. ${ }^{3}$ e \\ VICTORIA FILHO, R. ${ }^{4}$
}

\begin{abstract}
RESUMO - Em casa de vegetação, cinco experimentos foram desenvolvidos com o objetivo de avaliar a influência da profundidade de semeadura e da condição de cobertura do solo na emergência de plântulas de cinco espécies da família Convolvulaceae (Ipomoea hederifolia, I. nil, I. quamoclit, I. triloba e Merremia cissoides). Foi utilizada combinação fatorial entre quatro profundidades de semeadura $(0,20,40$ e $80 \mathrm{~mm}$ ) e duas condições de solo (exposto ou coberto com palha de cana-de-açúcar em quantidade proporcional a $10 \mathrm{t} \mathrm{ha}^{-1}$ ), com delineamento experimental de blocos ao acaso e quatro repetições. Foi realizada contagem diária do número de plântulas emersas e, ao final dos experimentos, calculou-se o índice de velocidade de emergência. Quanto à profundidade de semeadura no solo, maior emergência foi observada para as sementes que foram dispostas na superficie, tanto na presença quanto na ausência de palha. Considerando-se I. hederifolia e I. nil, não foi observado efeito da cobertura do solo, nem mesmo interação de profundidade e cobertura, sobre a emergência das espécies. Para I. quamoclit, observaram-se efeitos isolados da cobertura do solo e da profundidade de alocação das sementes, que indicaram maior adaptação da espécie para emergir em solo sem palhada superficial. Também para as espécies $I$. triloba e M. cissoides, a emergência foi inferior nas parcelas com palha distribuida na superfície do solo, quando comparadas àquelas sem palha, e, ainda, a presença de palha reduziu a velocidade de emergência e estabelecimento das plântulas.
\end{abstract}

Palavras-chave: Ipomoea, Merremia, corda-de-viola, biologia, Saccharum.

ABSTRACT - Five trials were developed under greenhouse conditions aiming to evaluate the influence of sowing depth and soil cover condition on seedling emergence of five Convolvulaceae family species (Ipomoea hederifolia, I. nil, I. quamoclit, I. triloba and Merremia cissoides). A factorial scheme was used for four sowing depths $(0,20,40$ and $80 \mathrm{~mm}$ ) and two soil conditions (exposed or covered with sugarcane straw in an amount proportional to 10 t ha $\mathrm{A}^{-1}$ ); arranged in a randomized block design and four replicates. Emerged seedlings were counted daily and, at the end of the trials, emergence index speed was calculated. Regarding soil-sowing depth, higher emergence was observed for seeds distributed on the soil surface, both in the presence and absence of straw. Considering emergence of $\boldsymbol{I}$. hederifolia and I. nil, no soil cover nor even depth $x$ cover interaction effects were observed. For I. quamoclit, isolated soil cover effects and seed distribution depth were observed, indicating better adaptability of the species to emerge in soil without the presence of straw on the surface. Also for the species I. triloba and $\boldsymbol{M}$. cissoides, emergence was lower in the plots with straw on the soil surface, compared to those without straw. In addition, straw distributed on the soil surface reduced emergence speed and seedling establishment.

Keywords: Ipomoea, Merremia, morningglory, biology, Saccharum

1 Recebido para publicação em 31.10.2008 e na forma revisada em 11.12.2009.

Parte da dissertação do primeiro autor apresentada à ESALQ/USP para obtenção do título de Mestre em Fitotecnia.

2 Engo-Agr ${ }^{\circ}$., Mestre em Fitotecnia, Escola Superior de Agricultura "Luiz de Queiroz" - ESALQ/USP, <vlabonia@ig.com.br>;

${ }^{3}$ Pós-graduandos em Fitotecnia - ESALQ/USP, Piracicaba-SP, <sjpcarvalho@yahoo.com.br>, <vhvmondo@yahoo.com.br>, <chiovato@esalq.usp.br>; ${ }^{4}$ Professor Titular do Departamento de Produção Vegetal - ESALQ/USP, Av. Pádua Dias, 11, Caixa Postal 09, 13418-900 Piracicaba-SP, <rvictori@esalq.usp.br> 


\section{INTRODUÇÃO}

No Brasil, poucos estudos foram realizados com o intuito de elucidar os mecanismos envolvidos na emergência de plantas daninhas, bem como a profundidade máxima a partir da qual as sementes são capazes de emergir. Segundo Toledo et al. (1993) e Brighenti et al. (2003), o conhecimento da profundidade na qual a plântula é capaz de emergir pode permitir a adoção de práticas de manejo pertinentes, como, por exemplo, o emprego de métodos mecânicos associados ou não a métodos químicos.

A profundidade em que sementes são capazes de germinar e produzir plântulas é variável entre as espécies e apresenta importância ecológica e agronômica (Guimarães et al., 2002). Muitas espécies de plantas daninhas, principalmente as que possuem sementes com poucas reservas, germinam quando dispostas em pequenas profundidades no solo, pois, em sua maioria, necessitam do estímulo luminoso. Uma vez que a luz é fortemente atenuada à medida que a profundidade no solo aumenta, normalmente sementes dessas espécies não são capazes de emergir em maiores profundidades. No entanto, há espécies que não necessitam do estímulo luminoso para dar início ao processo de germinação e que podem, portanto, emergir a partir de maiores profundidades. Esse fato possibilita a essas espécies maior capacidade de sobrevivência em áreas com perturbações por tratos culturais e pode também ter implicações importantes relacionadas ao controle por herbicidas aplicados ao solo (Canossa et al., 2007).

Além da profundidade em que as sementes estão posicionadas, a presença de palha na superfície do solo também tem implicação direta na emergência de muitas espécies de plantas daninhas, como no caso da cobertura morta resultante do corte mecanizado da cana-de-açúcar (Christoffoleti et al., 2007). As coberturas podem apresentar efeito indutor ou redutor na germinação das sementes e emergência de plântulas, dependendo da espécie constituinte da palha e da densidade de cobertura (Correia \& Rezende, 2002). Para Correia (2005), resíduos vegetais mantidos na superficie do solo alteram a umidade, luminosidade e temperatura deste. Também, o processo de decomposição da cobertura morta na superfície do solo libera uma série de compostos orgânicos, denominados aleloquímicos, que podem interferir na germinação e emergência das plantas daninhas. Os niveis de interferência normalmente variam em função da quantidade, composição e velocidade de decomposição dos resíduos.

Segundo Pitelli (1995), o efeito físico da cobertura morta reduz as chances de sobrevivência das plantas daninhas que possuem pequena quantidade de reservas nas sementes, que podem não ser suficientes para garantir a sobrevivência da planta no espaço a ser percorrido dentro da cobertura morta até ter acesso à luz e iniciar o processo fotossintético. Nesse sentido, Correia \& Durigan (2004) verificaram que 5,10 e $15 \mathrm{t} \mathrm{ha}^{-1}$ de palha sobre a superficie do solo inibiram a emergência de plântulas de Brachiaria decumbens e Sida spinosa; 10 e $15 \mathrm{t} \mathrm{ha}^{-1}$ de palha também inibiram a emergência de Digitaria horizontalis. No entanto, as espécies Ipomoea grandifolia e I. hederifolia mantiveram-se como plantasproblema, não sofrendo alteração no número de plântulas emersas; ainda, a presença de palha sobre o solo incrementou a emergência de plântulas de I. quamoclit.

Com o advento da colheita de cana-deaçúcar sem queima prévia (cana-crua), têm-se verificado alterações na flora infestante dos canaviais, como a seleção de espécies com sementes grandes e capacidade de germinar sob a camada de palha, com destaque para Euphorbia heterophylla e espécies da família Convolvulaceae (Pitelli \& Durigan, 2001; Christoffoleti et al., 2007; Cavenaghi et al., 2007). Conhecidas popularmente por corda-deviola, as espécies da família Convolvulaceae são plantas nativas da América do Sul, cujo ciclo biológico é longo, terminando após a maturação das culturas, o que tende a criar problemas na colheita, sobretudo em cana-deaçúcar, pois seus ramos se fixam aos colmos da cultura (Kissmann \& Groth, 1999; Lorenzi, 2000).

Considera-se que a profundidade de enterrio de sementes viáveis de plantas daninhas no solo e a cobertura vegetal morta têm efeito variável sobre a emergência, de acordo com a espécie. Nesse sentido, objetivou-se com este trabalho avaliar a influência da profundidade de semeadura e da condição de cobertura do 
solo (com ou sem palha de cana-de-açúcar) na emergência de plântulas de cinco espécies de plantas daninhas da família Convolvulaceae.

\section{MATERIAL E MÉTODOS}

Cinco experimentos foram desenvolvidos em casa de vegetação do Departamento de Produção Vegetal da Escola Superior de Agricultura Luiz de Queiroz - Universidade de São Paulo, Piracicaba-SP $\left(22^{\circ} 42^{\prime} 30^{\prime \prime}\right.$, $47^{\circ} 38^{\prime} 00^{\prime \prime} \mathrm{W}$ e $546 \mathrm{~m}$ de altitude), no mês de março de 2008. Cada experimento correspondeu ao estudo de uma espécie de planta daninha da família Convolvulaceae, sendo elas: Ipomoea hederifolia, I. nil, I. quamoclit, I. triloba e Merremia cissoides.

As sementes de todas as espécies foram adquiridas comercialmente na empresa AgroCosmos Produção e Serviços Rurais Ltda. (Engenheiro Coelho-SP). Para remover o efeito de dormência sobre os resultados experimentais, elas foram escarificadas quimicamente, utilizando-se ácido sulfúrico concentrado, durante intervalo de tempo definido para cada espécie por Azania et al. (2003). Após o intervalo estipulado, as sementes foram removidas do ácido, lavadas em água corrente e secas à sombra em temperatura ambiente.

O delineamento experimental adotado foi o de blocos ao acaso, com quatro repetições. Para todos os experimentos, os tratamentos foram organizados em esquema fatorial $4 \times 2$, considerando-se quatro níveis de profundidade de semeadura $(0,20,40$ e $80 \mathrm{~mm})$ e duas condições de solo (exposto ou coberto com palha de cana-de-açúcar em quantidade proporcional a $10 \mathrm{t} \mathrm{ha}^{-1}$ ). As unidades experimentais foram constituídas por vasos plásticos com $190 \mathrm{~mm}$ de diâmetro, $150 \mathrm{~mm}$ de altura e capacidade para 2,8 litros.

A semeadura foi realizada distribuindo-se 25 sementes por vaso nas profundidades desejadas e cobrindo-as com solo até altura pré-delimitada, constante para todas as parcelas. O solo utilizado, de textura francoarenosa, foi coletado em área experimental pertencente à ESALQ/USP, sendo peneirado para a retirada de torrões. As características químicas do solo estão apresentadas na Tabela 1. A palha de cana-de-açúcar utilizada para cobertura das parcelas foi proveniente da variedade RB815156, recolhida logo após a colheita mecânica em área da Usina Costa Pinto, em Piracicaba-SP. Em seguida, a palha foi picada e seca à sombra, em casa de vegetação, durante quatro dias, e então distribuída às parcelas.

O fundo dos vasos foi vedado com papelfiltro para evitar a perda de solo, que poderia proporcionar heterogeneidade às parcelas. Cada vaso foi alocado sobre um vasilhame plástico de maior diâmetro e sem orifícios, visando à manutenção do regime hídrico das parcelas. O solo foi inicialmente irrigado até a saturação e, posteriormente, sua umidade foi controlada diariamente, repondo-se a água nos vasilhames sempre que necessário, de modo que se mantivesse nivel próximo a $80 \%$ da capacidade de campo.

A emergência das plântulas foi verificada diariamente até 14 dias após a semeadura (DAS). No final desse período, calculou-se a porcentagem total de emergência para cada unidade experimental, bem como o indice de velocidade de emergência (IVE), adaptado de Maguire (1962):

$$
I V E=\sum\left(\frac{N S E}{D A S}\right)
$$

em que NSE é o número não acumulado de sementes emersas por 100 sementes, em cada data de avaliação (DAS).

Separadamente, para cada experimento, os dados foram submetidos ao teste $\mathrm{F}$ para

Tabela 1 - Propriedades químicas do solo utilizado nos experimentos. Piracicaba-SP, 2008

\begin{tabular}{|c|c|c|c|c|c|c|c|c|c|c|c|c|}
\hline M.O. & P resina & $\mathrm{K}$ & $\mathrm{Ca}$ & $\mathrm{Mg}$ & $\mathrm{H}+\mathrm{Al}$ & $\mathrm{AL}$ & $\mathrm{AB}$ & $\mathrm{CTC}$ & $\mathrm{V}$ & $\mathrm{m}$ & $\mathrm{pH}$ \\
\hline$\left(\mathrm{g} \mathrm{dm}^{-3}\right)$ & $\left(\mathrm{mg} \mathrm{dm}^{-3}\right)$ & \multicolumn{9}{|c|}{$\left(\mathrm{mmol}_{\mathrm{c}} \mathrm{dm}^{-3}\right)$} & \multicolumn{3}{|c|}{$(\%)$} & $\left(\mathrm{CaCl}_{2}\right)$ \\
\hline 11 & 5 & 1,1 & 11 & 11 & 6 & 0 & 47 & 36,1 & 50 & 0 & 5,0 \\
\hline
\end{tabular}


análise da variância. Quando houve efeito significativo da cobertura do solo, os niveis desse fator foram comparados por meio do teste t a 5\% de significância. Quando significativas, as profundidades foram ajustadas a regressões exponenciais.

\section{RESULTADOS E DISCUSSÃO}

Com a aplicação do teste $\mathrm{F}$ na análise da variância, constatou-se significância do fator cobertura do solo apenas para algumas espécies (experimentos). Resultado semelhante foi observado para a significância da interação de profundidade da semente e cobertura do solo. Assim, para maior compreensão dos procedimentos estatísticos de comparação do efeito de cobertura do solo e análise por regressões (profundidade), optou-se por apresentar o quadro da análise da variância dos cinco experimentos, em formato resumido (Tabela 2).

Considerando-se I. hederifolia, não foi observado efeito da cobertura do solo, nem mesmo interação de profundidade e cobertura, sobre a emergência da espécie (Tabela 2). Isso indica que as sementes da espécie possuem habilidade de germinar em condição de menor disponibilidade de luz e menor amplitude

Tabela 2 - Resumo do quadro da análise da variância para emergência e índice de velocidade de emergência (IVE) de espécies de cordade-viola (Ipomoea e Merremia), quando relacionadas às fontes de variação do experimento ${ }^{1 /}$, bem como à interação destas. Piracicaba-SP, 2008

\begin{tabular}{|c|c|c|c|c|c|}
\hline Espécie & Variável & Fonte de Variação & $\mathrm{GL}^{2 /}$ & $\mathrm{F}$ & $\operatorname{Pr}>\mathrm{Fc}$ \\
\hline \multirow{6}{*}{ I. hederifolia } & \multirow{3}{*}{ Emergência } & Profundidade & 3 & $19,801 * *$ & $<0,001$ \\
\hline & & Cobertura & 1 & $0,253^{\mathrm{NS}}$ & 0,620 \\
\hline & & Interação & 3 & $0,501^{\mathrm{NS}}$ & 0,685 \\
\hline & \multirow{3}{*}{ IVE } & Profundidade & 3 & $36,583 * *$ & $<0,001$ \\
\hline & & Cobertura & 1 & $0,021^{\mathrm{NS}}$ & 0,887 \\
\hline & & Interação & 3 & $1,354^{\mathrm{NS}}$ & 0,284 \\
\hline \multirow{6}{*}{ I. nil } & \multirow{3}{*}{ Emergência } & Profundidade & 3 & $75,153 * *$ & $<0,001$ \\
\hline & & Cobertura & 1 & $0,000^{\mathrm{NS}}$ & 0,998 \\
\hline & & Interação & 3 & $0,076^{\mathrm{NS}}$ & 0,973 \\
\hline & \multirow{3}{*}{ IVE } & Profundidade & 3 & $109,074 * *$ & $<0,001$ \\
\hline & & Cobertura & 1 & $1,640^{\mathrm{NS}}$ & 0,214 \\
\hline & & Interação & 3 & $0,484^{\mathrm{NS}}$ & 0,697 \\
\hline \multirow{6}{*}{ I. quamoclit } & \multirow{3}{*}{ Emergência } & Profundidade & 3 & $136,291 * *$ & $<0,001$ \\
\hline & & Cobertura & 1 & $9,568 * *$ & 0,006 \\
\hline & & Interação & 3 & $1,198^{\mathrm{NS}}$ & 0,335 \\
\hline & \multirow{3}{*}{ IVE } & Profundidade & 3 & $111,401 * *$ & $<0,001$ \\
\hline & & Cobertura & 1 & $10,602 * *$ & 0,004 \\
\hline & & Interação & 3 & $1,733^{\mathrm{NS}}$ & 0,191 \\
\hline \multirow{6}{*}{ I. triloba } & \multirow{3}{*}{ Emergência } & Profundidade & 3 & $174,538 * *$ & $<0,001$ \\
\hline & & Cobertura & 1 & $8,850^{* *}$ & 0,007 \\
\hline & & Interação & 3 & $1,206^{\mathrm{NS}}$ & 0,332 \\
\hline & \multirow{3}{*}{ IVE } & Profundidade & 3 & $248,646^{* *}$ & $<0,001$ \\
\hline & & Cobertura & 1 & $19,684 * *$ & $<0,001$ \\
\hline & & Interação & 3 & $3,657^{*}$ & 0,029 \\
\hline \multirow{6}{*}{ M. cissoides } & \multirow{3}{*}{ Emergência } & Profundidade & 3 & $60,843 * *$ & $<0,001$ \\
\hline & & Cobertura & 1 & $14,091 * *$ & 0,001 \\
\hline & & Interação & 3 & $0,868^{\mathrm{NS}}$ & 0,473 \\
\hline & \multirow{3}{*}{ IVE } & Profundidade & 3 & $85,500 * *$ & $<0,001$ \\
\hline & & Cobertura & 1 & $36,867 * *$ & $<0,001$ \\
\hline & & Interação & 3 & $8,398 * *$ & 0,001 \\
\hline
\end{tabular}

1/ Blocos ao acaso; dados transformados por $\sqrt{x+0,5}$; ${ }^{2}$ GL - graus de liberdade; ** significativo a $1 \%$ de probabilidade; Ns - não significativo. 
térmica sob a camada de palha, por exemplo. Condição semelhante foi observada para $I$. nil (Tabela 2). Essa característica de germinação e emergência pode conferir vantagens adaptativas para infestações de áreas de canade-açúcar com colheita sem queima. Esses resultados estão em concordância com os de Azania et al. (2002), que estudaram a resposta biológica de espécies dos gêneros Ipomoea e Merremia submetidas à germinação sob camada de $15 \mathrm{t} \mathrm{ha}^{-1}$ de palha de cana-de-açúcar. Esses autores constataram que, entre todas as espécies estudadas, I. hederifolia foi a que teve a germinação menos comprometida pela camada de palha.

A emergência e o IVE de I. hederifolia estão apresentados na Figura 1. Vale destacar que a emergência máxima ajustada da espécie foi de apenas $27,4 \%$, porém houve emergência de plântulas mesmo quando as sementes foram alocadas a $80 \mathrm{~mm}$ de profundidade (Figura $1 \mathrm{~A}$ ). Ambas as variáveis foram adequadamente ajustadas pelo modelo exponencial, caracterizando menor emergência e velocidade de emergência para alocação de sementes em maiores profundidades. As equações de ajuste também estão apresentadas na Figura 1 e podem contribuir para elaboração de modelos mais complexos de estimativa da emergência da espécie ou mesmo para comparação com outros resultados experimentais. Também para I. nil observou-se ajuste das variáveis ao modelo exponencial, mas houve maior tendência à ausência de plântulas, com cerca de $1 \%$ de emergência das sementes alocadas a $80 \mathrm{~mm}$ de profundidade (Figura $2 \mathrm{~A}$ ).
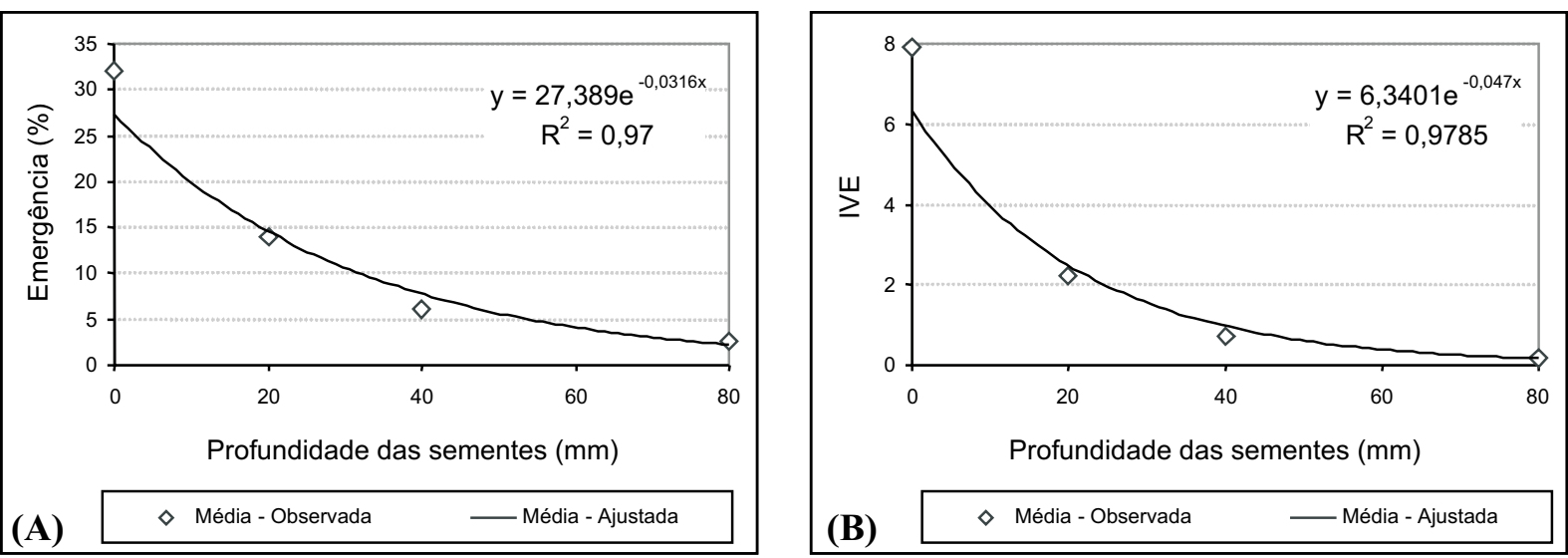

Figura 1 - Emergência (A) e índice de velocidade de emergência - IVE (B) de Ipomoea hederifolia quando semeada em diferentes profundidades. Piracicaba-SP, 2008.
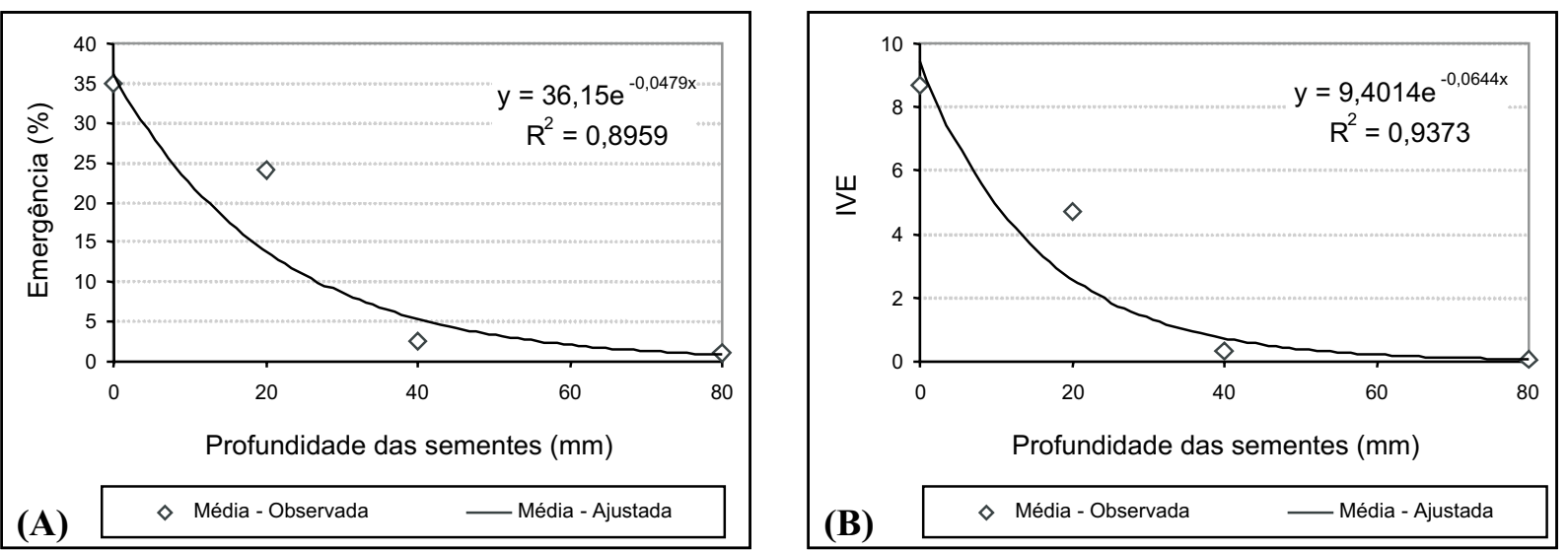

Figura 2 - Emergência (A) e índice de velocidade de emergência - IVE (B) de Ipomoea nil quando semeada em diferentes profundidades. Piracicaba-SP, 2008 
Apesar de essas duas espécies não serem afetadas pela cobertura morta sobre o solo em relação à sua germinação, a emergência de ambas foi afetada pela condição de maior enterrio. Essa tendência de decréscimo na emergência em maiores profundidades também tem sido constatada em outras espécies do gênero Ipomoea. Em estudo com a planta daninha I. lacunosa, Oliveira \& Norsworthy (2006) obtiveram decréscimo de emergência conforme aumentaram a profundidade das sementes no solo, chegando à germinação de $50 \%$ a $40 \mathrm{~mm}$ de profundidade e apenas $4 \%$ a $100 \mathrm{~mm}$. Trabalhando com três espécies de Ipomoea, Gomes et al. (1978) obtiveram o máximo de emergência das sementes na faixa de profundidade entre 13 e $25 \mathrm{~mm}$ para as três espécies, chegando a obter reduções na germinação da margem de $80 \%$ à profundidade de $75 \mathrm{~mm}$.

Considerando I. quamoclit, observaram-se efeitos isolados da cobertura do solo e da profundidade de alocação das sementes, porém sem interação destes (Tabela 2). A ocorrência de efeito da cobertura do solo justificou a aplicação do teste $t$ para comparação das médias das variáveis. Confirmaram-se emergência e IVE diferenciais, indicando maior adaptação da espécie para emergir em solo sem palhada superficial (Tabela 3). Em termos de germinação, o mesmo foi observado para I. triloba e M. cissoides (Tabela 3). Resultado semelhante também foi encontrado por Azania et al. (2002), que observaram redução de $46 \%$ na germinação de I. quamoclit sob palha, quando comparado à ausência desta. A redução das variáveis foi expressiva quando se alocaram sementes em maior profundidade, com tendência à ausência de emergência para sementes distribuídas a $80 \mathrm{~mm}$ (Figura 3).

Entre os experimentos (espécies), condição diferenciada foi observada para I. triloba e M. cissoides (Tabela 2). Para a variável emergência, observaram-se efeitos da profundidade de alocação da semente no solo, bem como efeito da cobertura com palha de cana-deaçúcar, sem ocorrência de interação. Por outro lado, para a variável IVE, constatou-se interação dos efeitos, indicando que a resposta biológica em pelo menos uma profundidade diferiu das demais respostas em razão do sistema de cobertura do solo (Tabela 2).
Tabela 3 - Emergência (\%) e índice de velocidade de emergência (IVE) de espécies de corda-de-viola (Ipomoea e Merremia) sob influência da palha de cana-de-açúcar. Piracicaba-SP, 2008

\begin{tabular}{|l|l|r|r|c|}
\hline \multirow{2}{*}{ Espécie } & \multirow{2}{*}{ Variável $^{1}{ }^{1}$} & \multicolumn{2}{|c|}{ Palhada } & \multirow{2}{*}{$\begin{array}{c}\text { CV } \\
\text { (\%) }\end{array}$} \\
\cline { 3 - 4 } & & Presente & Ausente & ( quamoclit \\
\cline { 3 - 4 } & Emergência & $14,75 \mathrm{~b}$ & $20,75 \mathrm{a}$ & 20,56 \\
\cline { 2 - 4 } & IVE & $2,61 \mathrm{~b}$ & $4,32 \mathrm{a}$ & 18,30 \\
\hline I. triloba & Emergência & $25,00 \mathrm{~b}$ & $31,75 \mathrm{a}$ & 16,18 \\
\hline M. cissoides & Emergência & $8,75 \mathrm{~b}$ & $16,75 \mathrm{a}$ & 26,16 \\
\hline
\end{tabular}

1/ Dados referentes à média de todas as profundidades; Médias seguidas por letras minúsculas iguais, na linha, não diferem entre si pelo teste $\mathrm{t}$ a $5 \%$ de significância; Dados originais apresentados, porém previamente transformados por $\sqrt{x+0,5}$

A redução gradativa das variáveis avaliadas devido à profundidade de distribuição das sementes de I. triloba e $M$. cissoides também foi ajustada adequadamente ao modelo exponencial. Maiores niveis de emergência foram observados quando se distribuíram sementes de I. triloba na superfície do solo, com ou sem presença de palhada, da ordem de $76 \%$ (Figura 4A). Ainda, com a decomposição da interação de efeitos, foi possivel identificar menor IVE (DMS (Cobertura) $=2,5$ ) para as sementes que estiveram sob influência da palha de cana-de-açúcar (Figura 4B), mostrando que, além de a palha ter reduzido a porcentagem de plântulas emergidas (Tabela 3), ela também atrasou a emergência e o desenvolvimento inicial das plântulas da espécie.

Os resultados verificados para $M$. cissoides estão em concordância com aqueles observados para I. triloba. Também para $M$. cissoides, maiores níveis de emergência foram constatados quando da distribuição de sementes na superficie das parcelas (Figura 5A). Por sua vez, a redução do IVE provocada pela cobertura do solo com palha de cana-de-açúcar foi mais evidente $\left(\mathrm{DMS}_{\text {(Cobertura) }}=1,85\right)$. A razão dos indices máximos de IVE (sem palha/com palha) foi da ordem 3 , que indica que as sementes desta espécie estão mais adaptadas a germinar em superficie (Tabela 3; Figura $5 \mathrm{~B})$, provavelmente pela maior disponibilidade de luz e temperatura.

Em geral, todas as espécies deste trabalho apresentaram maiores porcentagens de germinação na superficie do solo do que quando 

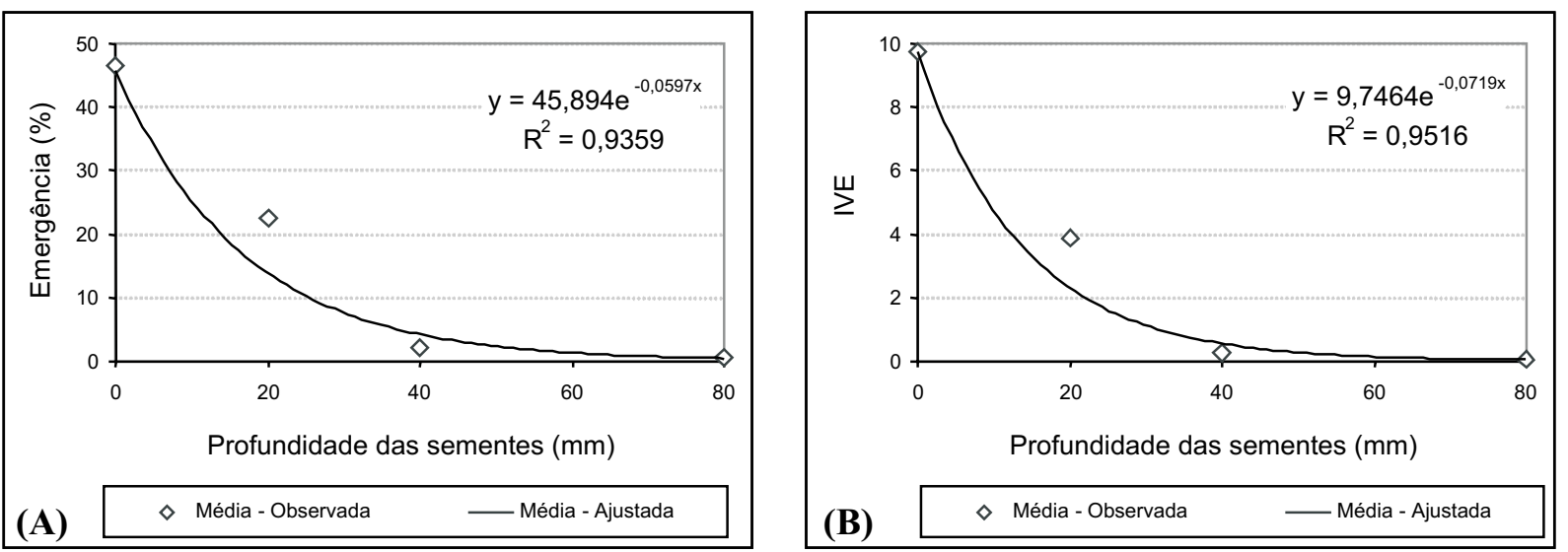

Figura 3 - Emergência (A) e índice de velocidade de emergência - IVE (B) de Ipomoea quamoclit quando semeada em diferentes profundidades. Piracicaba-SP, 2008.
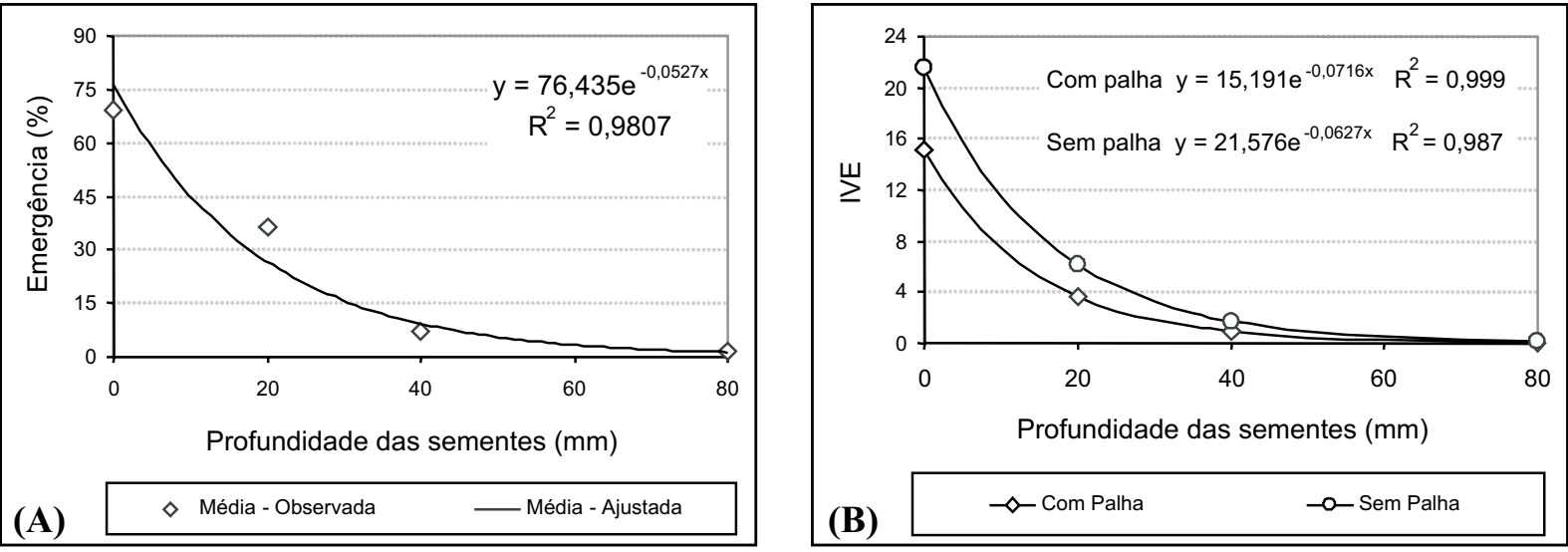

Figura 4 - Emergência (A) e índice de velocidade de emergência - IVE (B) de Ipomoea triloba quando semeada em diferentes profundidades. Efeito da cobertura do solo observado apenas para IVE - DMS (cobertura) $_{2,50 .}$ Piracicaba-SP, 2008.
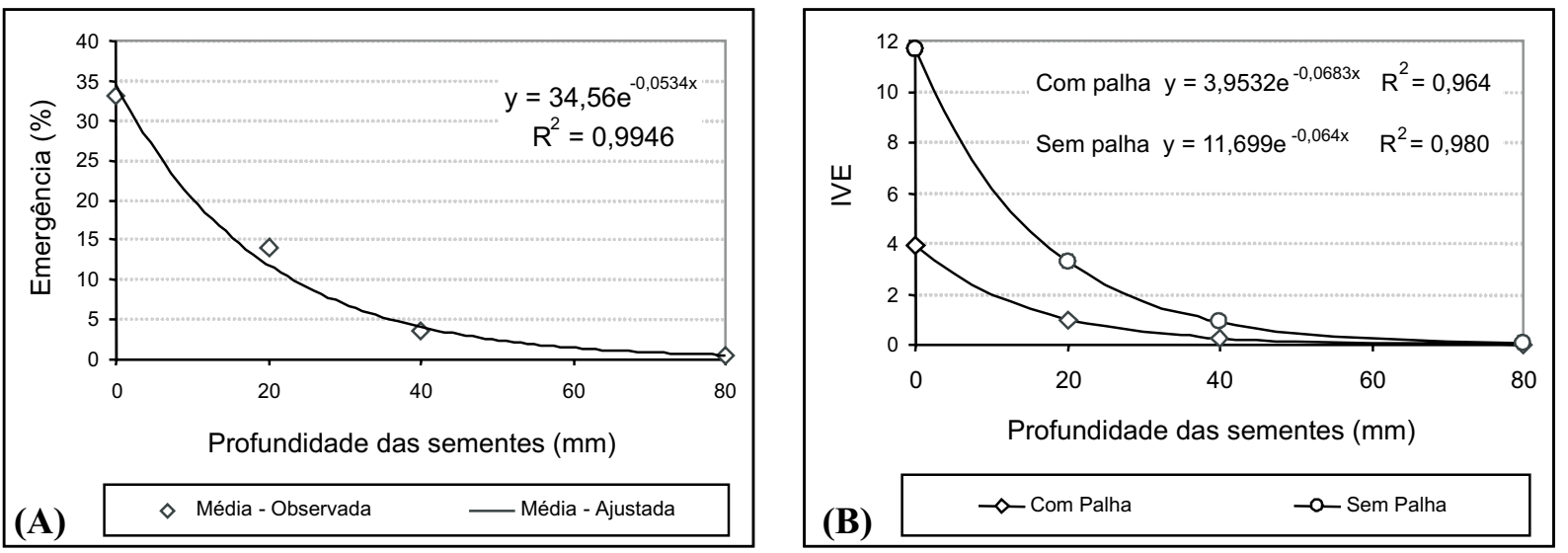

Figura 5 - Emergência (A) e índice de velocidade de emergência - IVE (B) de Merremia cissoides quando semeada em diferentes profundidades. Efeito da cobertura do solo observado apenas para IVE - DMS (cobertura) $_{1,85}$. Piracicaba-SP, 2008. 
enterradas. De forma semelhante, a planta daninha buva (Conyza bonariensis) emergiu predominantemente a partir da superficie do solo ou à profundidade de $5 \mathrm{~mm}$, em solo de textura franco-arenosa (Wu et al., 2007). Outros autores também observaram comportamento semelhante para outras espécies de plantas daninhas, mono ou dicotiledôneas. Martins (2008), estudando Borreria densiflora; Dias et al. (2008), avaliando Commelina benghalensis; Wilson Jr. et al. (2006) estudando Murdannia nudiflora; Carvalho et al. (2005), trabalhando com Chloris polydactyla; e Carmona (1993), estudando Rumex crispus, constataram melhor emergência das sementes dispostas em superficie quando comparado com sementes enterradas.

Por outro lado, germinação e emergência de Ipomoea purpurea já foram relatadas em profundidades abaixo de $150 \mathrm{~mm}$. Em campo, I. purpurea e I. hederacea tiveram emergência superior a $50 \%$ quando enterradas na profundidade de $75 \mathrm{~mm}$. Contudo, a emergência máxima em casa de vegetação ocorreu em profundidades entre 13 e $25 \mathrm{~mm}$ e 25 a $50 \mathrm{~mm}$ em experimento de campo (Wilson \& Cole, 1966). Trabalhando com I. turbinata, Chandler et al. (1977) obtiveram emergência máxima de sementes na faixa de profundidade entre 25 e $75 \mathrm{~mm}$, ainda com $40 \%$ de emergência ocorrendo aos $150 \mathrm{~mm}$. Conforme se pode notar, outros trabalhos avaliaram o efeito da profundidade de enterrio de sementes das espécies do gênero Ipomoea, porém dificilmente são encontrados experimentos com as espécies estudadas neste trabalho. Ainda, vale ressaltar que os resultados obtidos neste trabalho podem não se expressar em campo, razão pela qual outras pesquisas devem ser conduzidas para avaliar a resposta biológica das espécies à prática agrícola.

O fato de as espécies apresentarem melhores germinações em superfície pode ser consequência da maior disponibilidade de luz que há nessa condição, além de haver menor impedimento físico à germinação e maior alternância de temperatura. Assim, quanto à profundidade da semente no solo, maior emergência de todas as espécies foi observada quando as sementes foram dispostas em superficie, tanto na presença quanto na ausência de palha. Considerando-se I. hederifolia e I. nil, não foi observado efeito da cobertura do solo, nem mesmo interação de profundidade e cobertura, sobre a emergência da espécie. Para I. quamoclit, observaram-se efeitos isolados da cobertura do solo e da profundidade de alocação das sementes, que indicaram maior adaptação da espécie para emergir em solo sem palhada superficial. Também para as espécies I. triloba e $M$. cissoides, a emergência foi inferior nas parcelas com palha distribuída na superficie do solo, quando comparadas àquelas sem palha, e, ainda, a presença de palha reduziu significativamente a velocidade de emergência e o estabelecimento das plântulas.

\section{LITERATURA CITADA}

AZANIA, A. A. P. M. et al. Interferência da palha de cana-deaçúcar (Saccharum spp. ) na emergência de espécies de plantas daninhas da família Convolvulaceae. Planta Daninha, v. 20, n. 2, p. 207-212, 2002.

AZANIA, A. A. P. M. et al. Métodos de superação de dormência em sementes de Ipomoea e Merremia. Planta Daninha, v. 21, n. 2, p. 203-209, 2003.

BRIGHENTI, A. M.; VOLL, E.; GAZZIERO, D. L. P. Biologia e manejo do Cardiospermum halicacabum. Planta Daninha, v. 21, n. 2, p. 229-237, 2003.

CANOSSA, R. S. et al. Sowing depth affecting Alternanthera tenella seedlings emergence. Planta Daninha, v. 25, n. 4, p. 719-725, 2007.

CARMONA, R. Influência das variações estacionais e profundidade de sementes no solo na dormência e germinação em Rumex crispus L. Planta Daninha, v. 11, n. 1/2, p. 29-36, 1993.

CARVALHO, S. J. P. et al. Influência da luz, temperatura e profundidade da semente no solo sobre a germinação e emergência do capim-branco (Chloris polydactyla). B. Inf. SBCPD., v. 12, n. 2, p. 11-15, 2005.

CAVENAGHI, A. L. et al. Dinâmica do herbicida amicarbazone (Dinamic) aplicado sobre palha de cana-deaçúcar (Saccharum officinarum). Planta Daninha, v. 25, n. 4, p. 831-837, 2007.

CHANDLER, J. M.; MUNSON, R. L.; VAUGHAN, C. E. Purple moonflower: Emergence, growth, reproduction. Weed Sci., v. 25, n. 2, p. 163-167, 1977.

CHRISTOFFOLETI, P. J. et al. Conservation of natural resources in Brazilian agriculture: implications on weed biology and management. Crop Protec., v. 26, n. 3, p. 383-389, 2007. 
CORREIA, N. M. Palhas de sorgo associadas ao herbicida imazamox no controle de plantas daninhas na cultura da soja em sucessão. Planta Daninha, v. 23, n. 3, p. 483-489, 2005.

CORREIA, N. M.; DURIGAN, J. C. Emergência de plantas daninhas em solo coberto com palha de cana-de-açúcar.

Planta Daninha, v. 22, n. 1, p. 11-17, 2004.

CORREIA, N. M.; REZENDE, P. M. Manejo integrado de plantas daninhas na cultura da soja. Lavras: UFLA, 2002. 55 p. (Boletim Agropecuário, 51)

DIAS, A. C. R. et al. Germinação e emergência da trapoeraba (Commelina benghalensis) influenciada pela luz e pela profundidade da semente no solo. In: CONGRESO DE LA ASOCIACIÓN LATINOAMERICANA DE MALEZAS, 18., Ouro Preto, 2008. Resumos Expandidos... Ouro Preto: Embrapa Milho e Sorgo/SBCPD, 2008. 8 p.

GOMES, L. F.; CHANDLER, J. M.; VAUGHAN, C. E. Aspects of germination, emergence, and seed production of three Ipomoea taxa. Weed Sci., v. 26, n. 3, p. 245-248, 1978.

GUIMARÃES, S. C.; SOUZA, I. F.; PINHO, E. V. R. V. Emergência de Tridax procumbens em função de profundidade de semeadura, do conteúdo de argila no substrato e da incidência de luz na semente. Planta Daninha, v. 20, n. 3, p. 413-419, 2002.

KISSMANN, K. G.; GROTH, D. Plantas infestantes e nocivas. 2.ed. São Paulo: BASF, 1999. v. 2. 978 p.

LORENZI, H. Plantas daninhas do Brasil: terrestres, aquáticas, parasitas e tóxicas. 3.ed. Nova Odessa: Instituto Plantarum, 2000. $608 \mathrm{p}$

MAGUIRE, J. D. Speed of germination-aid in selection and evaluation for seedling emergence and vigor. Crop Sci., v. 2, n. 1, p. 176-177, 1962.
MARTINS, B. A. B. Biologia e manejo da planta daninha Borreira densiflora DC. 2008. 169 f. Dissertação (Mestrado em Agronomia) - Escola Superior de Agricultura "Luiz de Queiroz", Universidade de São Paulo, Piracicaba, 2008 .

OLIVEIRA, M.; NORSWORTHY, J. K. Pitted morningglory (Ipomoea lacunosa) germination and emergence as affected by environmental factors and seeding depth. Weed Sci., v. 54, n. 5, p. 910-916, 2006.

PITELLI, R. A. Dinâmica de plantas daninhas no sistema de plantio direto. In: CONGRESSO BRASILEIRO DA CIÊNCIA DAS PLANTAS DANINHAS, 19., 1995 , Florianópolis. Palestras... Florianópolis: SBCPD, 1995. p. $5-12$.

PITELLI, R. A.; DURIGAN, J. C. Ecologia das plantas daninhas no sistema de plantio direto. In: DIAZ ROSSELLO, R. (Coord.). Siembra directa en Cono Sur. Montevideo: PROCISUR, 2001. p. 203-210.

TOLEDO, R. E. B.; KUVA, M.; ALVES, P. L. C. A. Fatores que afetam a germinação e a emergência de Xanthium strumarium L.: dormência, qualidade de luz e profundidade de semeadura. Planta Daninha, v. 11, n. 1/2, p. 15-20, 1993.

WILSON Jr., D. G. et al. Doveweed (Murdannia nudiflora) germination and emergence as affected by temperature and seed burial. Weed Sci., v. 54, n. 6, p. 1000-1003, 2006.

WILSON, H. P.; COLE, R. H. Morningglory competition in soybeans. Weeds, v. 14, n. 1, p. 49-51, 1966.

WU, H. et al. Germination, persistence, and emergence of flaxleaf fleabane (Conyza bonariensis). Weed Biol. Manag., v. 7, n. 3, p. 192-199, 2007. 